\title{
Review Article \\ ZnO-Based Transparent Conductive Thin Films: Doping, Performance, and Processing
}

\author{
Yanli Liu, Yufang Li, and Haibo Zeng \\ College of Material Science and Technology, Nanjing University of Aeronautics and Astronautics, Nanjing 210016, China \\ Correspondence should be addressed to Haibo Zeng; zeng.haibo.nano@gmail.com
}

Received 21 December 2012; Accepted 2 February 2013

Academic Editor: Xijin Xu

Copyright (C) 2013 Yanli Liu et al. This is an open access article distributed under the Creative Commons Attribution License, which permits unrestricted use, distribution, and reproduction in any medium, provided the original work is properly cited.

\begin{abstract}
$\mathrm{ZnO}$-based transparent conductive thin films have attracted much attention as a promising substitute material to the currently used indium-tin-oxide thin films in transparent electrode applications. However, the detailed function of the dopants, acting on the electrical and optical properties of $\mathrm{ZnO}$-based transparent conductive thin films, is not clear yet, which has limited the development and practical applications of $\mathrm{ZnO}$ transparent conductive thin films. Growth conditions such as substrate type, growth temperature, and ambient atmosphere all play important roles in structural, electrical, and optical properties of films. This paper takes a panoramic view on properties of $\mathrm{ZnO}$ thin films and reviews the very recent works on new, efficient, low-temperature, and high-speed deposition technologies. In addition, we highlighted the methods of producing ZnO-based transparent conductive film on flexible substrate, one of the most promising and rapidly emerging research areas. As optimum-processing-parameter conditions are being obtained and their influencing mechanism is becoming clear, we can see that there will be a promising future for $\mathrm{ZnO}$ based transparent conductive films.
\end{abstract}

\section{Introduction}

Transparent conductive oxides (TCOs), capable of transporting electrical charge and transmitting visible photon, are necessary for use as transparent electrodes in flat panel displays such as liquid crystal displays (LCDs), plasma display panels, electronic paper displays, light-emitting-diodes (LEDs) [1], and touch panels $[2,3]$. A carrier concentration on the order of $10^{20} \mathrm{~cm}^{-3}$ or higher and a band-gap energy above $3 \mathrm{eV}$ are usually required for high conductivity and transmittance [4]. Various TCO thin films consisting of impurity-doped $\mathrm{SnO}_{2}$ $\left(\mathrm{SnO}_{2}: \mathrm{Sb}\right.$ and $\left.\mathrm{SnO}_{2}: \mathrm{F}\right), \mathrm{In}_{2} \mathrm{O}_{3}\left(\mathrm{In}_{2} \mathrm{O}_{3}: \mathrm{Sn}\right.$, or ITO), and $\mathrm{ZnO}$ ( $\mathrm{ZnO}: \mathrm{Al}$ and $\mathrm{ZnO}: \mathrm{Ga}$ ) films have been researched so far in this field $[5,6]$. Among them, tin-doped indium-oxide (ITO) is the one in practical use $[7,8]$. However, with the market of ITO expanding, a stable supply may be difficult to ensure because of the high cost and scarcity of indium $[9,10]$.

Fortunately, $\mathrm{ZnO}$ thin films are a promising alternative to the commonly used ITO, which are low cost, nontoxic, highly durable against hydrogen plasma compared to ITO [11]. Besides, it has a more proper work function for the transparent contact cathode electrodes of transparent OLEDs
[12]. Nevertheless, many problems associated with substituting ZnO-based TCO films for ITO still exist. Figure 1 visually describes structural, optical, electrical properties of zinc oxide. In LCD applications, stability in various environments has to be improved when films become thinner. [13]. In OLEDs applications, preparation technology of lowtemperature and plasma damage-free films on flexible substrate have to be optimized.

For the design and realization of $\mathrm{ZnO}$-based devices, one of the most significant issues is doping, which necessarily involves the heavy doping with trivalent elements from the group III ( $\mathrm{Al}, \mathrm{Ga}$, In). Minami summed up the resistivity of impurity-doped binary compound TCO films reported among thirty years and found that the obtained minimum resistivity of impurity-doped $\mathrm{ZnO}$ films is still decreasing, while $\mathrm{SnO}_{2}$ and $\mathrm{In}_{2} \mathrm{O}_{3}$ films have essentially remained unchanged [4]. Such trend indicates the possible significant promotion of $\mathrm{ZnO}$-based TCO films.

$\mathrm{ZnO}$ films have been prepared through various kinds of methods $[14,15]$ and each of them has its own advantages and drawbacks. In this paper, sputtering, chemical vapor deposition (CVD), and pulsed laser deposition (PLD) are 
TABle 1: Properties of ZnO films with different dopants prepared by PLD.

\begin{tabular}{lccccc}
\hline Dopants & Optimum content in target $(\%)$ & Thickness $(\mathrm{nm})$ & Resistivity $(\Omega \cdot \mathrm{cm})$ & Transmittance $(\%)$ & Reference \\
\hline $\mathrm{Al}$ & 2 & 500 & $4.5 \times 10^{-4}$ & $88 \%$ & \\
$\mathrm{Ga}$ & 5 & 200 & $8.12 \times 10^{-4}$ & $>90 \%$ & $>35]$ \\
$\mathrm{In}$ & 40 & $>1000$ & $4.02 \times 10^{-4}$ & $>85 \%$ & $>30 \%$ \\
$\mathrm{~F}$ & 2 & 200 & $4.83 \times 10^{-4}$ & $\sim 36]$ \\
$\mathrm{Si}$ & 2 & $\sim 150$ & $6.2 \times 10^{-4}$ & {$[25]$} & {$[37]$} \\
\hline
\end{tabular}

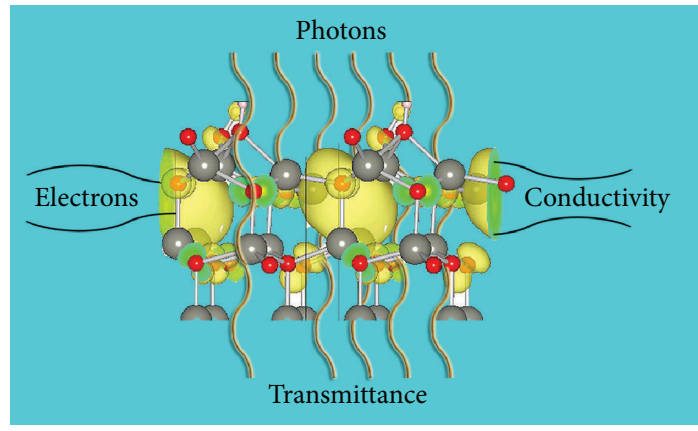

FIGURE 1: A picture visually describing structural, optical, electrical properties of zinc oxide. Revised from [38]. Copyright 2012, American Chemistry Society.

described in details, since ZnO-based TCO films based on these methods can get the highest quality. The first two methods allowing large area deposition make them the most advanced and efficient deposition techniques for $\mathrm{ZnO}$ film. Even if the films are prepared by the same method, thickness, substrate, growth temperature, dopant, and their content will play a crucial role in structural, electrical, and optical properties of films. Therefore, whether we can optimize the fabrication of high-quality doped zinc oxide thin films at low cost determines the future of $\mathrm{ZnO}$-based TCO films. The structural, optical, electrical properties of doped $\mathrm{ZnO}$ are summarized with particular emphasis on influence of doping on the properties of $\mathrm{ZnO}$ thin films, which are responsible for the properties of films. In addition, recent progress on film preparation is introduced.

\section{Different Dopant Elements}

Several elements are doped in $\mathrm{ZnO}$ films, such as B $[16,17]$, $\mathrm{Al}, \mathrm{Ga}$, In (from group III elements) [18], F (from group VII element) [19], and so forth. Among them the most studied are Al-doped $\mathrm{ZnO}$ and Ga-doped $\mathrm{ZnO}$. In Section 2, we focus on recent research on $\mathrm{Al}, \mathrm{Ga}$ doping, and codoping. The position of the dopant atoms and solubility limit can be related to the film preparation methods. For example, in the spray pyrolysis technique, $\mathrm{In}$ and $\mathrm{Ga}$ is more efficient than $\mathrm{Al}$ since the $\mathrm{Al}$ atoms are preferably at interstitial sites of the $\mathrm{ZnO}$ lattice and decrease the mobility [20].

Some reported electrical and optical properties of $\mathrm{ZnO}$ films with different dopants prepared by PLD are summarized in Table 1. Each dopant was at its appropriate content and all films were fabricated under optimum-processingparameter conditions to achieve lower resistivity and higher transmittance.

2.1. Group III Elements Doping. The ionic radius of $\mathrm{Al}^{3+}$ is $0.54 \AA$, which is smaller than that of $\mathrm{Zn}^{2+}(0.74 \AA)$. So the $\mathrm{Al}^{3+}$ can occupy the place of $\mathrm{Zn}^{2+}$ in lattice easily, leading to a reduction of the lattice parameter. In comparison with $\mathrm{Al}^{3+}, \mathrm{Ga}^{3+}$ has similar ionic radius to $\mathrm{Zn}^{2+}$ ions, which minimizes the $\mathrm{ZnO}$ lattice deformations even at higher doping concentrations $[18,21]$. This may explain the reason why the best electrical properties of $\mathrm{ZnO}$-based films are observed in Ga-doped ZnO thin films [22].

The conductive property of $\mathrm{ZnO}$ thin films is primarily dominated by electrons generated by oxygen vacancies and charge donation. Geng and his coworkers [23] investigated the effect of $\mathrm{Al}$ concentration on the electrical properties of $\mathrm{ZnO}: \mathrm{Al}$ thin films grown on $\mathrm{Si}(100)$ substrate by atomic layer deposition. The crystallinity of the film degenerated while resistivity was found to decrease with increasing $\mathrm{Al}$ doping concentration $\left(9.36 \times 10^{-4} \Omega \cdot \mathrm{cm}\right.$ at maximal doping concentration 2.7 at.\%).

$\mathrm{Al}$ is incorporated beyond the thermodynamic solubility limit, even within the limit, the relationship between $\mathrm{Al}$ content and resistivity is not monotonous [24]. The resistivity of the AZO film decreased with an increase of the $\mathrm{Al}$ content up to 7 at.\% and then increased at a high $\mathrm{Al}$ content of 8 at.\% (Figure 2). At high $\mathrm{Al}$ concentration, $\mathrm{Al}$ exists in the form of $\mathrm{Al}_{2} \mathrm{O}_{3}$, resulting in deleterious effects to the electrical properties of the films. According to many other reports, the relationship between conduction characteristics and concentration of other elements doping is similar to that of $\mathrm{Al}$ doping.

Fluorine is another dopant to improve the conductivity of the films [19]. Unlike aluminum and other elements in group III, effect of fluorine in $\mathrm{ZnO}$ is less discussed. Fluorine incorporates into the lattice by substituting oxygen atoms due to the comparability of ionic radius (F-: $1.17 \AA, \mathrm{O}^{2-}: 1.22 \AA$ ). Actually, ZnO:F films have good combination properties. Cao et al. [25] prepared FZO films via pulsed laser deposition, getting a resistivity of $4.8 \times 10^{-4} \Omega \cdot \mathrm{cm}$, carrier concentration of $5.43 \times 10^{20} \mathrm{~cm}^{-3}$, and Hall mobility of $23.8 \mathrm{~cm}^{2} \mathrm{~V}^{-1} \mathrm{~s}^{-1}$, respectively. The average optical transmittance in the entire visible wavelength region was higher than $90 \%$.

2.2. Codoping. Difference of radii between doping ions and $\mathrm{Zn}^{2+}$ ions or $\mathrm{O}^{2-}$ ions will result in variation of lattice constant and degeneration of crystallinity in zinc oxide. 


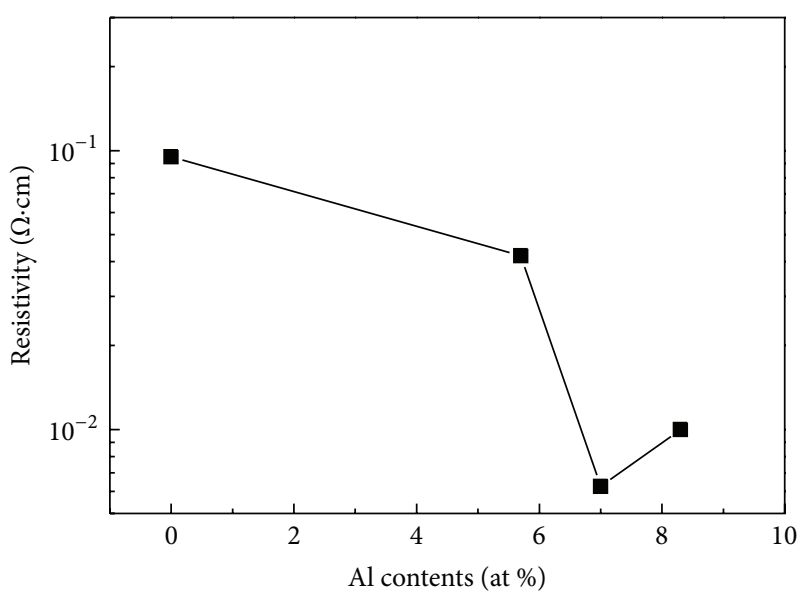

FIGURE 2: Resistivity as a function of $\mathrm{Al}$ contents from 0 to 8.4 at.\% achieved by Hall measurement at room temperature [24]. Copyright 2011, The Electrochemical Society.

This issue could be partially resolved by codoping, which has led to an upsurge study in recent years [26-28]. High quality of films deposited by Shin et al. has confirmed the advantages of codoping [29]. As Ga concentration increased from 0.5 to 2 at $\%$, the peak intensity of the (0002) plane and carrier concentration for $\mathrm{Mg}$ and $\mathrm{Ga}$ codoped $\mathrm{ZnO}$ thin films (MGZO) increase compared with that of pure $\mathrm{ZnO}$ and $\mathrm{Mg}$ doped $\mathrm{ZnO}$ thin films, as shown in Figure 3 [29], implying the substitution of $\mathrm{Ga}^{3+}$ ions with $\mathrm{Zn}^{2+}$ ions (ionic radius of $\mathrm{Ga}^{3+}$, $\mathrm{Mg}^{2+}$, and $\mathrm{Zn}^{2+}$ is $0.062 \mathrm{~nm}, 0.057 \mathrm{~nm}$, and $0.060 \mathrm{~nm}$, resp.). What is more, the MGZO structure was stabilized greatly in this method. The low electrical resistivity and wide band gap energy of MGZO thin films can be ascribed to the dopant of $\mathrm{Ga}$ and $\mathrm{Mg}$, respectively.

\section{Doping Concentration}

3.1. Concentration-Dependent Conductivity. Zinc oxide, as a transparent oxide with band-gap energy of $3.37 \mathrm{eV}$ [30], can satisfy the optical properties requirement of TCO without doping. However, the carrier concentration of intrinsic $\mathrm{ZnO}$ is roughly $10^{6} \mathrm{~cm}^{-3}$ at room temperature [31], which is much lower than that of TCO films for practical application. In general, an introduction of dopants affords an increase in carrier concentration, that is,

$$
n_{0} \cdot p_{0}=n_{i}^{2}
$$

where $n_{0}$ is the concentration of conductive electrons, $p_{0}$ is the concentration of hole, and $n_{i}$ is $s$ intrinsic carrier concentration in $\mathrm{ZnO}$. Doping directly affects carrier concentration and influences conductivity in turn. Although introduced impurities are necessary, but not more is better. Its concentration must have a limitation; otherwise, very high doping levels will result in high free carrier absorption, high plasma resonance reflectivity, and low visible wavelength transparency (Figure 2). Even though it seems difficult to improve electrical conduction while maintaining the optical transmission, there is the potential to achieve both through improving the microstructure of the films and increasing the carrier mobility. Obviously, it is important to deconstruct the influence of intentionally introduced impurities on electrical properties of $\mathrm{ZnO}$ to realize any type of device applications.

3.2. Concentration-Dependent Optical Gap Shift. The opticalgap shift is contributed by two competing effects, BursteinMoss (B-M) band-filling effect and band-gap narrowing (BGN) effect (Figure 4). The well-known optical band-gap $\left(E_{g \text { op }}\right)$ blue shift $[32,33]$ in heavily doped semiconductors occurs because the lower states in the conduction band are blocked. Conversely, band-gap narrowing is caused by exchange interactions in the free-electron gas and electrostatic interactions between free electrons and ionized impurities. The fact that BGN effect is largely compensated by B-M effect and temperature or doping are two influence factors in the $E_{g \text { op }}$ behavior makes it difficult to separate these two effects by means of current experiments.

$\mathrm{Lu}$ and coworkers [34] found that $E_{g \text { op }}$, evaluated from optical absorption spectra, was mainly related to the carrier concentrations and so intrinsic to Al content. The optical gap increased with the electron concentration when $n_{e} \leq$ $4.2 \times 10^{19} \mathrm{~cm}^{-3}$, which could be fully interpreted by a modified Burstein-Moss effect; A sudden decrease in energy gap occurred at 5.4-8.4 $\times 10^{19} \mathrm{~cm}^{-3}$, consistent with the Mott criterion for a SMT. Above the critical values, the band gap increased again (see Figure 5). Further exploration in this issue is needed to promote energy band engineering in $\mathrm{ZnO}$ based TCO films.

\section{Effect of Growth Conditions}

4.1. Preparation Methods. Among various preparation methods, pulsed laser deposition (PLD) is more appropriate for precise controlling of morphology and composition of the grown materials. Park et al. and Agura et al. [22, 39] prepared AZO and GZO thin films on glass substrates with a low resistivity on the order of $10^{-5} \Omega \cdot \mathrm{cm}$ by PLD, respectively. Resistivity on the order of $10^{-5} \Omega \cdot \mathrm{cm}$ is the best result for $\mathrm{ZnO}$ films ever reported and there is a general agreement on the better performances in terms of conductivity for $\mathrm{ZnO}$ films grown by PLD than those obtained via other techniques. However, the problems of stability and cost most probably constrained the future development of this method in manufacture on a large scale.

Magnetron sputtering is one of the deposition methods in practical use. It was found that the lowest resistivity prepared by this method is still on the order of $10^{-4} \Omega \cdot \mathrm{cm}$, higher than the resistivities obtain by PLD several years ago. Chemical-vapor-deposition is another industrially most advanced deposition techniques. How to increase growth rate and applied to continuous, in-line manufacturing is a vital issue. Illiberi et al. deposited $\mathrm{ZnO}$ :Al films on glass by an industrially scalable metal organic chemical-vapordeposition (MOCVD) technique at atmospheric pressure $[40,41]$. In view of an industrial up-scale, the vaporized 


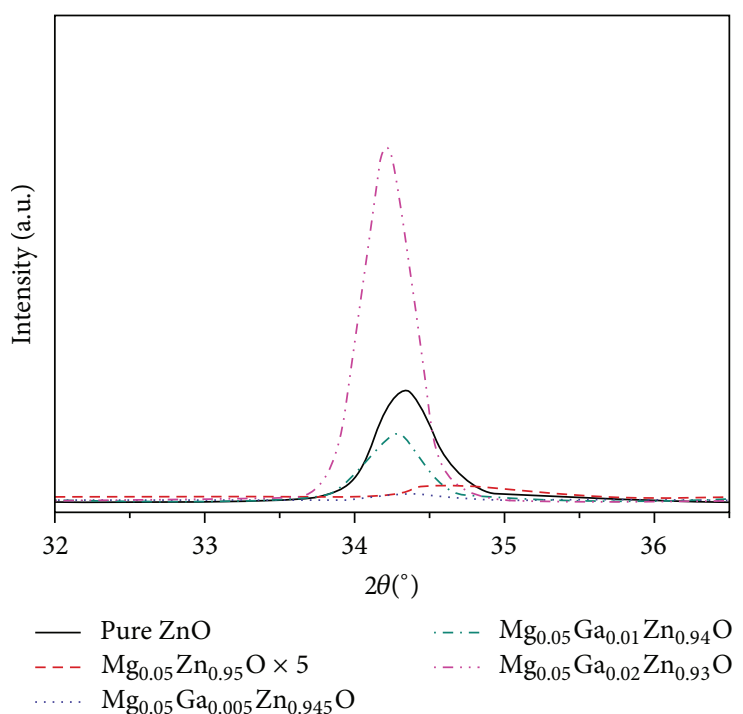

(a)

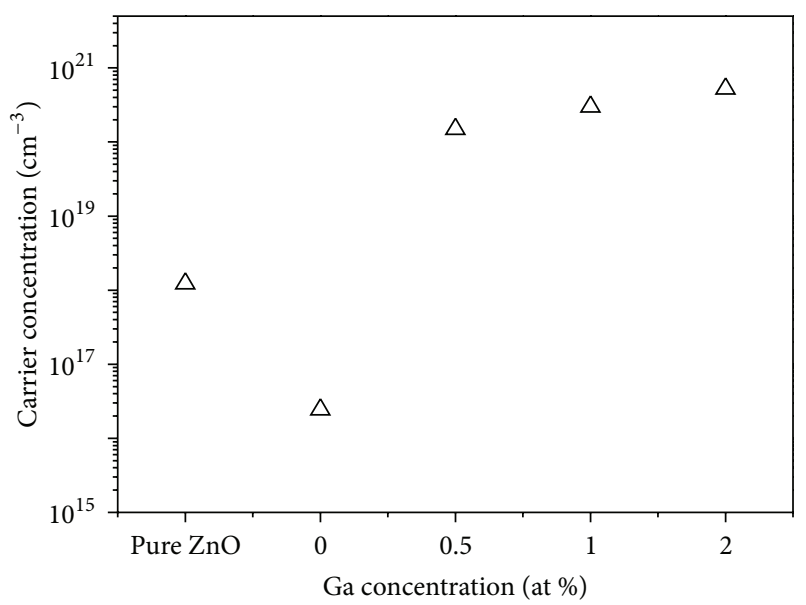

(b)

FIGURE 3: XRD patterns (a) and variation of the carrier concentration (b) of the pure ZnO, MZO, and MGZO thin films deposited at different Ga concentration [29]. Copyright 2011, American Chemistry Society.

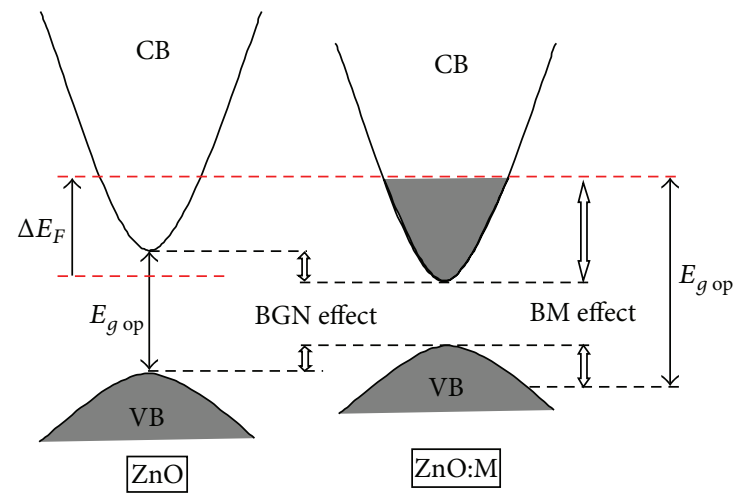

Figure 4: Band-gap renormalization and Burstein-Moss (B-M) band-filling effect contributions to the $E_{g \text { op }}$.

precursors, that is, diethylzinc (DEZ), Tertiary-butanol (tBUT), and trimethylaluminum (TMA), can be injected in different deposition zones, where each layer is deposited. Then, each zone installed along the same production line continuous, realizing in-line manufacturing. Schematic of an industrial atmospheric-pressure MOCVD system is shown in Figure 6. A maximum growth rate was found at a deposition temperature of $480^{\circ} \mathrm{C}$, for which $\mathrm{ZnO}_{x}: \mathrm{Al}$ films show good crystalline quality, high conductivity $(R<10 \Omega / \square$ for film thicknesses above $1050 \mathrm{~nm}$ ), and good transmittance $(>85 \%$ in the visible range).

Sol-gel method is an attractive liquid-phase routes for obtaining thin films due to its advantages of easy control of the film composition and fabrication of a large area thin film with low cost. Luo et al. [45] developed a versatile film-deposition process combining microwave-assisted nonaqueous sol-gel process with dip-coating. The resistivity of

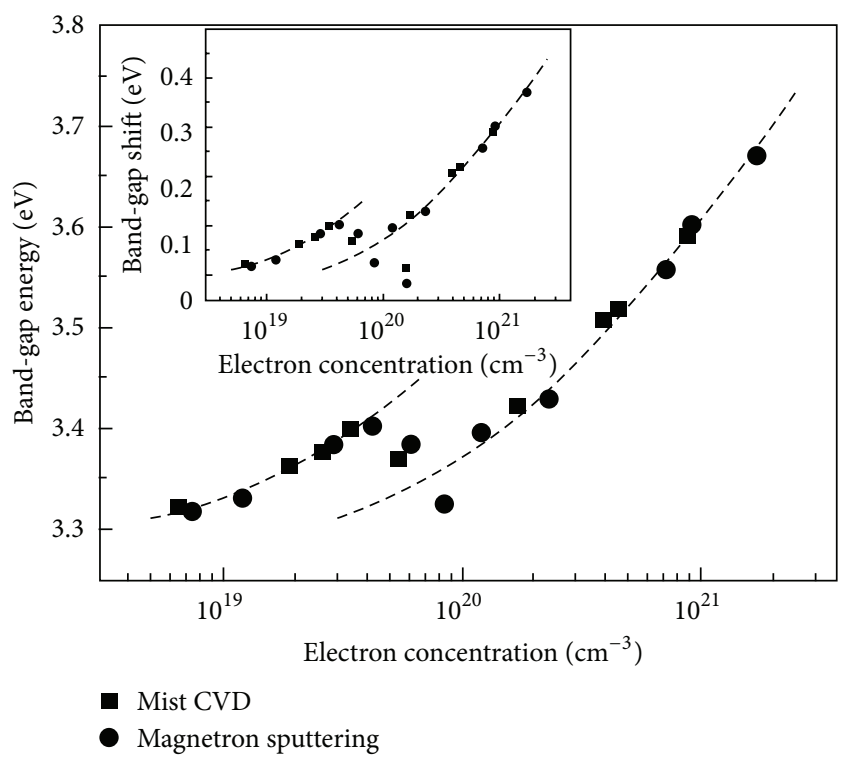

FIGURE 5: Band-gap energy as a function of electron concentration in AZO [34]. Copyright 2007, American Institute of Physics.

obtained films was a little high (minimum resistivity is $2.35 \times$ $10^{-2} \Omega \cdot \mathrm{cm}$ ) but their results are still promising on the way to the development of liquid-phase routes. To produce TCO films of good quality, every step of sol-gel method, including synthesis of nanoparticles, preparation of dispersions, thinfilm processing, and postannealing, has to be optimized.

4.2. Substrate Type. Up to now, transparent conductive films have been prepared on plenty of different substrates, such as glass, sapphire, and polymer. Polymeric substrates, 


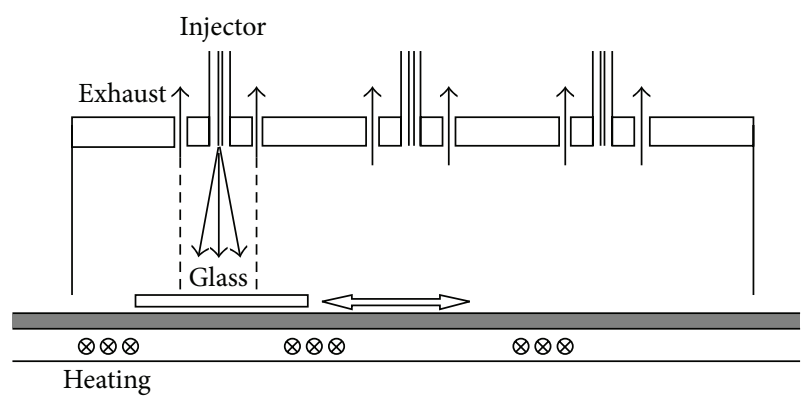

FIGURE 6: Schematic of an industrial atmospheric-pressure MOCVD system. Films have been deposited by using one injector. The system can be upscaled for industrial production by installing multiples injectors [40]. Copyright 2011, Elsevier.

polyethylene-terephthalate (PET) [46], polycarbonate (PC) [47], aspolyphthalamide (PPA) are drawing increasing attention due to their merits of light weight, low cost, ability to flex, curve, roll, fold small volume and promising application in organic light-emitting diodes (OLEDs) [48, 49].

Substrates nature alone may still affect microstructures (crystallization, morphology) and electrical properties of films. Esmaili-Sardari et al. have a research on conductivity type dependent on different substrates [50]. All films grown on boron doped $\mathrm{p}$-Si have n-type conductivity at low Hall Effect temperatures and p-type conductivity at high Hall Effect temperatures but films grown n-type substrate show ntype behavior for the entire Hall temperatures range from 80 to $350 \mathrm{~K}$, suggesting that the differences in nearly substrates surfaces could affect intrinsic defects and concentrations as well as the $\mathrm{ZnO}$ (0001) surface termination.

Shin et al. prepared thin films of Ga-doped $\mathrm{ZnO}$ (GZO) on glass and $\mathrm{Al}_{2} \mathrm{O}_{3}$ (0001) substrates by using $\mathrm{RF}$ magnetron sputtering under the same processing conditions and found that individual grains with columnar shape are clearly observed in the GZO film on the glass substrate, as shown in Figure 7(a). However, it is difficult to distinguish individual grains in the GZO film on the $\mathrm{Al}_{2} \mathrm{O}_{3}$ substrate (Figure 7(b)). The superior crystal quality of the epitaxially grown GZO films on $\mathrm{Al}_{2} \mathrm{O}_{3}$ substrates compared to the polycrystalline GZO films on glass substrates afforded better electrical characteristics.

Clatot et al. measured the film crystallinity and stoichiometry, resistivity, and transmittance curves of Si-doped $\mathrm{ZnO}$ thin films deposited both on glass and PET substrates. Their results confirmed the strong dependence of the electrical and optical properties on substrate nature [46]. As the theoretical and experimental studies of the impact of hydroxylation, vacancies, interstitials, and extrinsic doping on the electronic properties of the polar $\mathrm{ZnO}$ (0002) surface done by Li et al. [38], we can have a study on the influence of substrate type on growth, defects, and the electronic properties of the $\mathrm{ZnO}$ thin films.

4.3. Growth Temperature. At high temperature, films exhibited higher doping efficiency, higher carrier concentration, lower resistivity, and higher Hall mobility. Lee et al. [43] investigated the temperature dependence of electrical resistivity and optical band gap of GZO thin films. The resistivity of films decreases from $9.61 \times 10^{-3}$ to $4.50 \times 10^{-4} \Omega \cdot \mathrm{cm}$ with the increases of deposition temperature from 100 to $500^{\circ} \mathrm{C}$ (Figure 8), and this can be attributed to substitutional doping increase and the grain boundary density decrease as the growth temperature rose.

Low growth temperature is required for the flexible substrates in OLEDs. However, the films always show poor properties at low growth temperature. This relationship does not mean all hope for low-temperature growth lost. In recent years, the growth of high quality films at low temperature on flexible substrates has attracted extensive attention owing to the rather low cost with many unique applications [51,52]. Clatot et al. successfully deposited Si-doped zinc oxide (SZO, Si $3 \%)$ thin films at a relatively low temperature $\left(\leq 150^{\circ} \mathrm{C}\right)$ by pulsed laser deposition (PLD). The SZO films deposited on PET substrates at $100^{\circ} \mathrm{C}$ exhibit a very promising resistivity of $9.0 \times 10^{-4} \Omega \cdot \mathrm{cm}[46]$. Reference [44, 53] introduced a process combining room-temperature PLD and direct pulsed laser recrystallization (DPLR). During DPLR, the AZO thin film undergoes recrystallization and growth while the underlying flexible substrate is retained at low temperature. Schematic of DPLR technique and temperature evolution of AZO film on different substrates carried out by multiphysics EM-HT simulation is shown in Figures 9(a) and 9(b), respectively. Recrystallization and growth of films reduce internal imperfections, resulting in higher conductivity, Hall mobility (increases from 6.56 to $10.12 \mathrm{~cm}^{2} / \mathrm{Vs}$ ), and higher transmittance. It is also worthy to note that the merit of no damaging on the underlying substrates makes this technology promising in various low temperature applications.

4.4. Ambient Atmosphere. In deposit technique, ablated species will loss kinetic energy due to collisions with the background gas molecules, resulting in different film density and morphology. Gas pressure, especially oxygen partial pressure, has received a lot of attention [24, 25]. Gondoni et al. [35] found that when the background gas $\left(\mathrm{O}_{2}\right)$ pressure changed from $0.01 \mathrm{~Pa}$ to $10 \mathrm{~Pa}$, resistivity remains the same and increases to a magnitude of $10^{-1} \Omega \cdot \mathrm{cm}$ upon reaching $10 \mathrm{~Pa}$ abruptly (black squares in Figure 10). The increasing resistivity at higher pressures derived from a lower concentration of oxygen vacancy, which reduces the number of free electrons in turn. In addition, the annealing treatment in air was observed to cause resistivity to increase (red dots in Figure 10), diminishing residual dependence on deposition conditions because oxygen vacancies are saturated. This variation relation has been also observed in other preparation methods $[5,54]$.

In CVD processing, the precursor pressure in CVD processing also showed strong influence on resistivity. Kim et al. [24] prepared AZO layers on glass substrates by LP$\mathrm{CVD}$ and found $\mathrm{Al}$ precursor, (Trimethylaluminum) showed strong influence on $\mathrm{Al}$ contents and resistivity of AZO.

4.5. Film Thickness. Film thickness is another factor for the electrical and optical properties in $\mathrm{ZnO}$-based TCO films, 


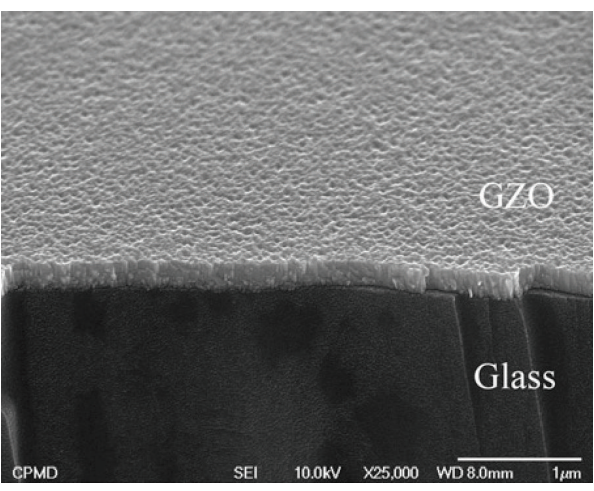

(a)

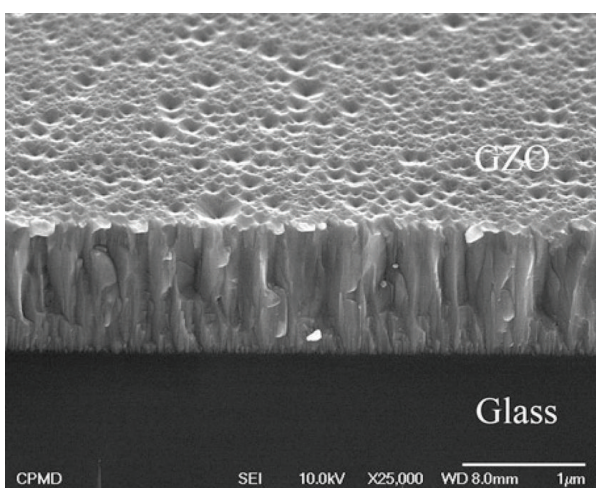

(c)

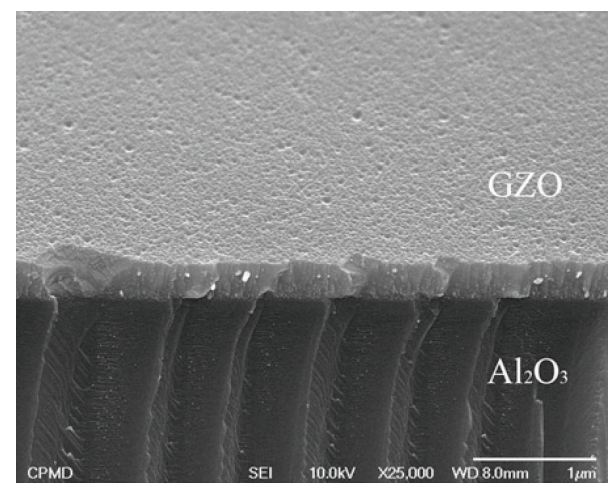

(b)

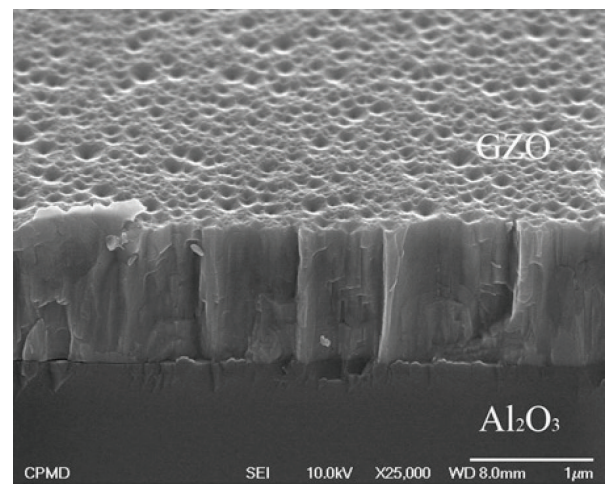

(d)

Figure 7: Cross-sectional FE-SEM images of (a) $200 \mathrm{~nm}$ thick GZO thin films on glass; (b) $200 \mathrm{~nm}$-thick $\mathrm{GZO}$ thin films on $\mathrm{Al}_{2} \mathrm{O}_{3}$ (0001) substrates; (c) $1000 \mathrm{~nm}$ thick GZO thin films on glass; (d) $1000 \mathrm{~nm}$ thick GZO thin films on $\mathrm{Al}_{2} \mathrm{O}_{3}(0001)$ substrates [42]. Copyright 2009 Materials Research Society.

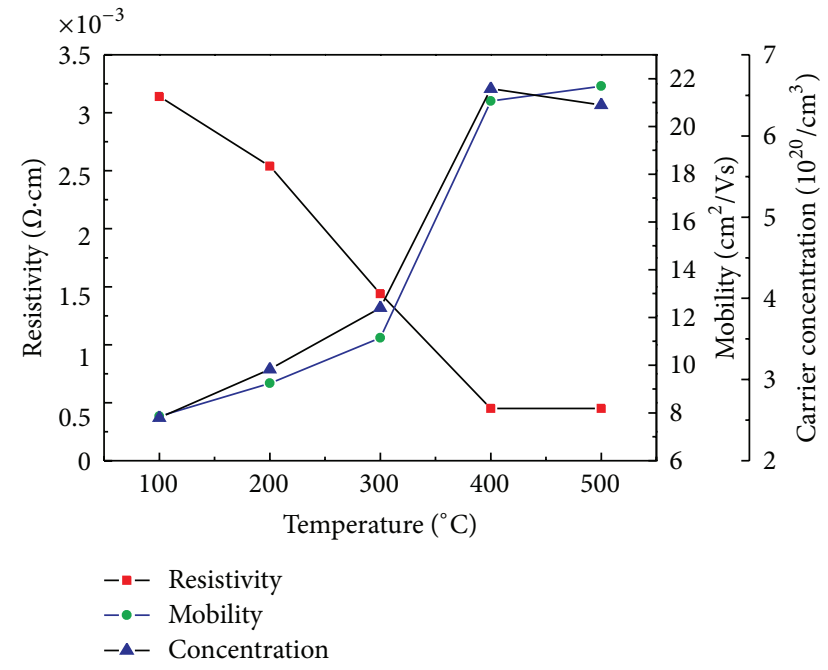

FIGURE 8: Resistivity, carrier concentration, and Hall mobility of GZO thin films as a function of deposition temperature in the range of RT to $500^{\circ} \mathrm{C}$ [43]. Copyright 2011, Elsevier.

which change from $\sim 50 \mathrm{~nm}$ to $\sim 2000 \mathrm{~nm}$. In magnetron sputtering and other deposition technique, $\mathrm{ZnO}$ films with various thicknesses are obtained by varying the deposition time, temperature, and power $[42,55]$. In sol-gel spin coating, films with various thicknesses are obtained with different repeating times of coating procedure $[26,45,56]$.

As we all know that electrical conductivity becomes better while transmittance may become poorer as the film thickness increases [55]. Shin et al. [42] investigated the effect of film thickness on the structural and electrical properties of Gadoped $\mathrm{ZnO}$ thin films. It was also found that the electrical resistivity difference between the films on the two substrates decreased from $9.48 \times 10^{-4} \Omega \cdot \mathrm{cm}$ to $1.45 \times 10^{-4} \Omega \cdot \mathrm{cm}$ with increasing the film thickness from $100 \mathrm{~nm}$ to $1000 \mathrm{~nm}$. In Figure 7 , the conductivity increases because of both the increase of grain size and the decrease of grain boundary scattering. On the other hand, more photons are adsorbed when the thickness increases according to the following:

$$
I=I_{0} \mathrm{e}^{-\alpha x}
$$

Here $I$ is the intensity of transmitted light, $I_{0}$ is the intensity of incident light, $\alpha$ is absorption coefficient, and $x$ can be treated as the film thickness. Due to these two opposite trends, it is difficult to balance the need for high conductivity with the need for high transparency. How to get thinner films with both excellent electrical and optical property is one of the main research tasks. 


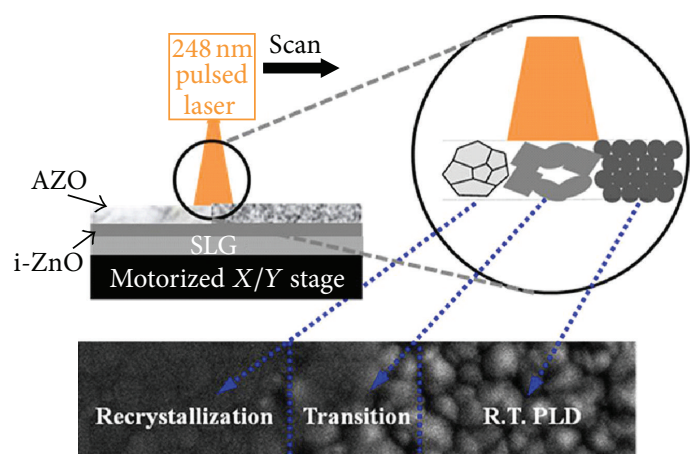

(a)

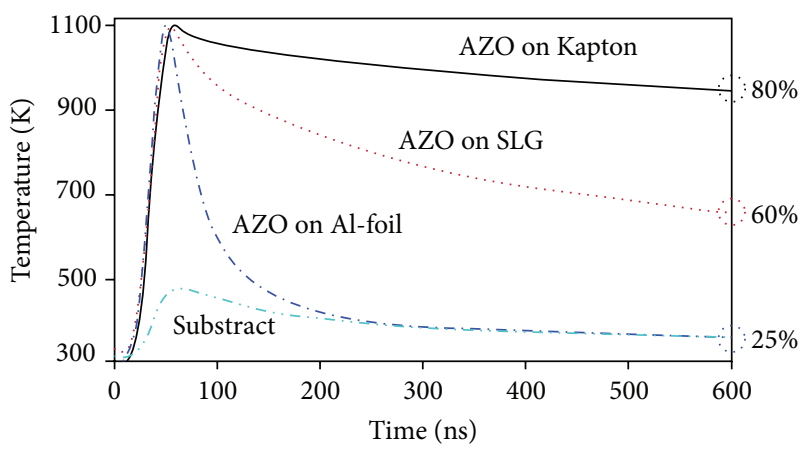

(b)

FIGURE 9: (a) Schematic of DPLR technique. (b) Temperature evolution of AZO film on different substrates carried out by multiphysics EMHT simulation. To reach $1100 \mathrm{~K}$ (peak temperature), laser fluence used is 50, 60, and $65 \mathrm{~mJ} / \mathrm{cm}^{2}$ for AZO film on Kapton, SLG, and Al-foil substrates, respectively [44]. Copyright 2012 American Institute of Physics.

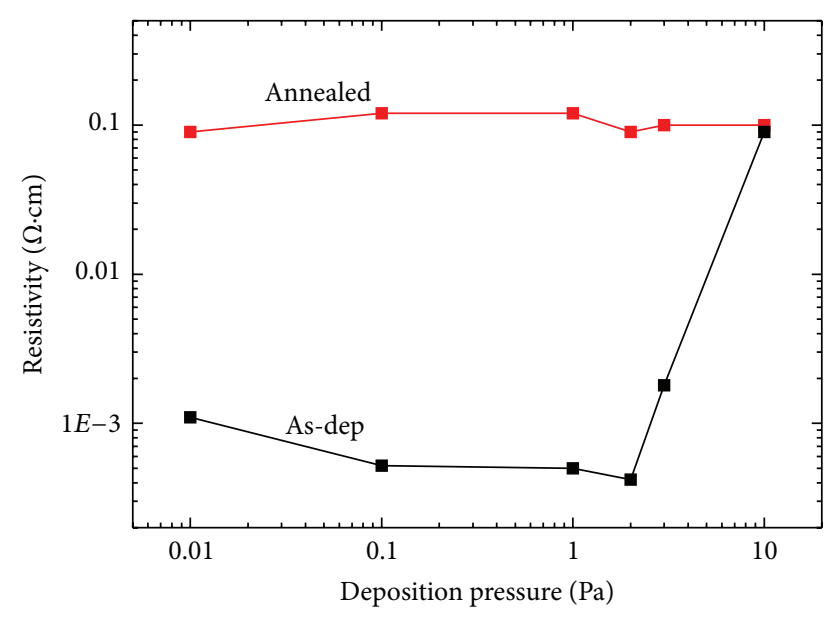

FIGURE 10: Resistivity as a function of deposition pressure for as-deposited (black squares) and annealed films (red dots) [35]. Copyright 2012, Elsevier.

\section{Summary}

In this paper, how dopants and growth conditions, such as substrate type, growth temperature, influence electrical and optical properties of $\mathrm{ZnO}$-based TCO films were discussed in a panoramic view. we reviewed recently published work on new, cheap, low-temperature, and high-speed deposition technology, highlighting methods of producing film on flexible substrate, the most promising and rapidly emerging research areas. However, more experimental works are needed to clarify the relationship between doping, processing, and property of $\mathrm{ZnO}$ thin films.

\section{Acknowledgments}

This work was supported by the Natural Science Foundation of China (Nos. 61222403), the Jiangsu Introduction Program of High-Level Innovative and Pioneering Talents, the Fundamental Research Funds for the Central Universities (Nos. 4015-56XIA12004 and 4015-56YAH11047), and by the
Opened Fund of the State Key Laboratory on Integrated Optoelectronics No. 20********.

\section{References}

[1] J. Song, Y. He, J. Chen et al., "Bicolor light-emitting diode based on zinc oxide nanorod arrays and poly(2-methoxy,5-octoxy)1,4-phenylenevinylene," Journal of Electronic Materials, vol. 41, no. 3, pp. 431-436, 2012.

[2] D. J. Rogers, F. H. Teherani, V. E. Sandana, and M. Razeghi, "ZnO thin films and nanostructures for emerging optoelectronic applications," in Proceedings of the 12th Optoelectronic Integrated Circuits, L. A. Eldada and E. H. Lee, Eds., January 2010.

[3] H. Zeng, X. Xu, Y. Bando et al., "Template deformationtailored $\mathrm{ZnO}$ nanorod/nanowire arrays: full growth control and optimization of field-emission," Advanced Functional Materials, vol. 19, no. 19, pp. 3165-3172, 2009.

[4] T. Minami, "Transparent conducting oxide semiconductors for transparent electrodes," Semiconductor Science and Technology, vol. 20, no. 4, pp. S35-S44, 2005.

[5] D. B. Buchholz, J. Liu, T. J. Marks, M. Zhang, and R. P. H. Chang, "Control and characterization of the structural, electrical, and optical properties of amorphous zinc-indium-tin oxide thin films," ACS Applied Materials \& Interfaces, vol. 1, no. 10, pp. 2147-2153, 2009.

[6] C. A. Hoel, T. O. Mason, J. F. Gaillard, and K. R. Poeppelmeier, "Transparent conducting oxides in the $\mathrm{ZnO}-\mathrm{In} 2 \mathrm{O} 3-\mathrm{SnO} 2$ system," Chemistry of Materials, vol. 22, no. 12, pp. 3569-3579, 2010.

[7] A. Stadler, "Transparent conducting oxides-an up-to-date overview," Materials, vol. 5, no. 4, pp. 661-683, 2012.

[8] C. G. Granqvist, "Transparent conductors as solar energy materials: a panoramic review," Solar Energy Materials and Solar Cells, vol. 91, no. 17, pp. 1529-1598, 2007.

[9] U.S.G. Survey, "Mineral Commodity Summaries," 2012.

[10] K. Ellmer, "Past achievements and future challenges in the development of optically transparent electrodes," Nature Photonics, vol. 6, no. 12, pp. 809-817, 2012.

[11] T. Minami, "Substitution of transparent conducting oxide thin films for indium tin oxide transparent electrode applications," Thin Solid Films, vol. 516, no. 7, pp. 1314-1321, 2008. 
[12] T. W. Kim, D. C. Choo, Y. S. No, W. K. Choi, and E. H. Choi, "High work function of Al-doped zinc-oxide thin films as transparent conductive anodes in organic light-emitting devices," Applied Surface Science, vol. 253, no. 4, pp. 1917-1920, 2006.

[13] T. Minami, "Present status of transparent conducting oxide thin-film development for Indium-Tin-Oxide (ITO) substitutes," Thin Solid Films, vol. 516, no. 17, pp. 5822-5828, 2008.

[14] H. Zeng, S. Yang, and W. Cai, "Reshaping formation and luminescence evolution of $\mathrm{ZnO}$ quantum dots by laser-induced fragmentation in liquid," Journal of Physical Chemistry C, vol. 115, no. 12, pp. 5038-5043, 2011.

[15] H. B. Zeng, X.-W. Du, S. C. Singh, S. A. Kulinich, S. Yang, and J. He, "Nanomaterials via laser ablation/irradiation in liquid: a review," Advanced Functional Materials, vol. 22, no. 7, pp. 13331353, 2012.

[16] A. Favier, D. Muñoz, S. Martín De Nicolás, and P. J. Ribeyron, "Boron-doped zinc oxide layers grown by metal-organic CVD for silicon heterojunction solar cells applications," Solar Energy Materials and Solar Cells, vol. 95, no. 4, pp. 1057-1061, 2011.

[17] Q. Huang, Y. Wang, S. Wang, D. Zhang, Y. Zhao, and X. Zhang, "Transparent conductive $\mathrm{ZnO}$ :B films deposited by magnetron sputtering," Thin Solid Films, vol. 520, no. 18, pp. 5960-5964, 2012.

[18] J. A. Sans, J. F. Sánchez-Royo, A. Segura, G. Tobias, and E. Canadell, "Chemical effects on the optical band-gap of heavily doped $\mathrm{ZnO}$ : MIII (M=Al,Ga,In): an investigation by means of photoelectron spectroscopy, optical measurements under pressure, and band structure calculations," Physical Review B, vol. 79, no. 19, Article ID 195105, 2009.

[19] D. S. Bhachu, I. P. Parkin, and G. Sankar, "Aerosol assisted chemical vapour deposition of transparent conductive Zinc oxide films," Chemistry of Materials, vol. 24, no. 24, pp. 47044710, 2012.

[20] P. Nunes, E. Fortunato, P. Tonello, F. Braz Fernandes, P. Vilarinho, and R. Martins, "Effect of different dopant elements on the properties of $\mathrm{ZnO}$ thin films," Vacuum, vol. 64, no. 3-4, pp. 281-285, 2002.

[21] J. L. Zhao, X. W. Sun, H. Ryu, and Y. B. Moon, "Thermally stable transparent conducting and highly infrared reflective Ga-doped $\mathrm{ZnO}$ thin films by metal organic chemical vapor deposition," Optical Materials, vol. 33, no. 6, pp. 768-772, 2011.

[22] S. M. Park, T. Ikegami, and K. Ebihara, "Effects of substrate temperature on the properties of $\mathrm{Ga}$-doped $\mathrm{ZnO}$ by pulsed laser deposition," Thin Solid Films, vol. 513, no. 1-2, pp. 90-94, 2006.

[23] Y. Geng, L. Guo, S. S. Xu et al., "Influence of Al doping on the properties of $\mathrm{ZnO}$ thin films grown by atomic layer deposition," Journal of Physical Chemistry C, vol. 115, no. 25, pp. 12317-12321, 2011.

[24] D. Kim, H. Kim, K. Jang, S. Park, K. Pillai, and J. Yi, "Electrical and optical properties of low pressure chemical vapor deposited Al-doped $\mathrm{ZnO}$ transparent conductive oxide for thin film solar cell," Journal of the Electrochemical Society, vol. 158, no. 4, pp. D191-D195, 2011.

[25] L. Cao, L. Zhu, J. Jiang, R. Zhao, Z. Ye, and B. Zhao, "Highly transparent and conducting fluorine-doped $\mathrm{ZnO}$ thin films prepared by pulsed laser deposition," Solar Energy Materials and Solar Cells, vol. 95, no. 3, pp. 894-898, 2011.

[26] T. Wang, Y. Liu, Q. Fang, M. Wu, X. Sun, and F. Lu, "Low temperature synthesis wide optical band gap $\mathrm{Al}$ and $(\mathrm{Al}, \mathrm{Na})$ co-doped ZnO thin films," Applied Surface Science, vol. 257, no. 6, pp. 2341-2345, 2011.
[27] D.-W. Kang, J.-Y. Kwon, D.-J. Lee, and M.-K. Han, "Boron and aluminum codoped $\mathrm{ZnO}$ transparent conducting films with high electrical stability," Journal of the Electrochemical Society, vol. 159, no. 2, p. H61, 2012.

[28] S. W. Shin, G. L. Agawane, I. Y. Kim et al., "Development of transparent conductive $\mathrm{Mg}$ and $\mathrm{Ga}$ co-doped $\mathrm{ZnO}$ thin films: effect of Mg concentration," Surface and Coatings Technology, 2012.

[29] S. W. Shin, I. Y. Kim, G. H. Lee et al., "Design and growth of quaternary $\mathrm{Mg}$ and $\mathrm{Ga}$ codoped $\mathrm{ZnO}$ thin films with transparent conductive characteristics," Crystal Growth \& Design, vol. 11, no. 11, pp. 4819-4824, 2011.

[30] H. Zeng, W. Cai, P. Liu et al., "ZnO-based hollow nanoparticles by selective etching: elimination and reconstruction of metalsemiconductor interface, improvement of blue emission and photocatalysis," ACS Nano, vol. 2, no. 8, pp. 1661-1670, 2008.

[31] D. P. Norton, Y. W. Heo, M. P. Ivill et al., "ZnO: growth, doping \& processing," Materials Today, vol. 7, no. 6, pp. 34-40, 2004.

[32] H. Zeng, W. Cai, J. Hu, G. Duan, P. Liu, and Y. Li, "Violet photoluminescence from shell layer of $\mathrm{Zn} / \mathrm{ZnO}$ core-shell nanoparticles induced by laser ablation," Applied Physics Letters, vol. 88, no. 17, Article ID 171910, 2006.

[33] H. Zeng, G. Duan, Y. Li, S. Yang, X. Xu, and W. Cai, "Blue luminescence of $\mathrm{ZnO}$ nanoparticles based on non-equilibrium processes: defect origins and emission controls," Advanced Functional Materials, vol. 20, no. 4, pp. 561-572, 2010.

[34] J. G. Lu, S. Fujita, T. Kawaharamura et al., "Carrier concentration dependence of band gap shift in n -type $\mathrm{ZnO}$ :Al films," Journal of Applied Physics, vol. 101, no. 8, Article ID 083705, 2007.

[35] P. Gondoni, M. Ghidelli, F. Di Fonzo et al., "Structural and functional properties of $\mathrm{Al}: \mathrm{ZnO}$ thin films grown by Pulsed Laser Deposition at room temperature," Thin Solid Films, vol. 520, no. 14, pp. 4707-4711, 2012.

[36] G. Socol, D. Craciun, I. N. Mihailescu et al., "High quality amorphous indium zinc oxide thin films synthesized by pulsed laser deposition," Thin Solid Films, vol. 520, no. 4, pp. 1274-1277, 2011.

[37] A. K. Das, P. Misra, and L. M. Kukreja, "Effect of Si doping on electrical and optical properties of $\mathrm{ZnO}$ thin films grown by sequential pulsed laser deposition," Journal of Physics D, vol. 42, no. 16, Article ID 165405, 2009.

[38] H. Li, L. K. Schirra, J. Shim et al., "Zinc oxide as a model transparent conducting oxide: a theoretical and experimental study of the impact of hydroxylation, bacancies, interstitials, and extrinsic doping on the electronic properties of the polar $\mathrm{ZnO}$ (0002) surface," Chemistry of Materials, vol. 24, no. 15, pp. 3044-3055, 2012.

[39] H. Agura, A. Suzuki, T. Matsushita, T. Aoki, and M. Okuda, "Low resistivity transparent conducting Al-doped $\mathrm{ZnO}$ films prepared by pulsed laser deposition," Thin Solid Films, vol. 445, no. 2, pp. 263-267, 2003.

[40] A. Illiberi, B. Kniknie, J. van Deelen et al., "Industrial high-rate $(\sim 14 \mathrm{~nm} / \mathrm{s})$ deposition of low resistive and transparent $\mathrm{ZnOx}: \mathrm{Al}$ films on glass," Solar Energy Materials and Solar Cells, vol. 95, no. 7, pp. 1955-1959, 2011.

[41] A. Illiberi, P. J. P. M. Simons, B. Kniknie et al., "Growth of ZnOx:Al by high-throughput CVD at atmospheric pressure," Journal of Crystal Growth, vol. 347, no. 1, pp. 56-61, 2012.

[42] S. W. Shin, S. M. Pawar, T. W. Kim, J. H. Moon, and J. H. Kim, "Effect of film thickness on the structural and electrical properties of $\mathrm{Ga}$-dopped $\mathrm{ZnO}$ thin films prepared on glass and 
Al2O3 (0001) substrates by RF magnetron sputtering method," Journal of Materials Research, vol. 24, no. 2, pp. 441-447, 2009.

[43] D.-H. Lee, K. Kim, Y. S. Chun, S. Kim, and S. Y. Lee, "Substitution mechanism of $\mathrm{Ga}$ for $\mathrm{Zn}$ site depending on deposition temperature for transparent conducting oxides," Current Applied Physics, vol. 12, no. 6, pp. 1586-1590, 2012.

[44] M. Y. Zhang, Q. Nian, and G. J. Cheng, "Room temperature deposition of alumina-doped zinc oxide on flexible substrates by direct pulsed laser recrystallization," Applied Physics Letters, vol. 100, no. 15, 2012.

[45] L. Luo, M. D. Rossell, D. Xie, R. Erni, and M. Niederberger, "Microwave-assisted nonaqueous Sol-Gel synthesis: from $\mathrm{Al}: \mathrm{ZnO}$ nanoparticles to transparent conducting films," ACS Sustainable Chemistry \& Engineering, vol. 1, no. 1, pp. 152160, 2013.

[46] J. Clatot, G. Campet, A. Zeinert, C. Labrugère, M. Nistor, and A. Rougier, "Low temperature Si doped $\mathrm{ZnO}$ thin films for transparent conducting oxides," Solar Energy Materials and Solar Cells, vol. 95, no. 8, pp. 2357-2362, 2011.

[47] L. Gong, J. Lu, and Z. Ye, "Transparent and conductive Gadoped $\mathrm{ZnO}$ films grown by $\mathrm{RF}$ magnetron sputtering on polycarbonate substrates," Solar Energy Materials and Solar Cells, vol. 94, no. 6, pp. 937-941, 2010.

[48] L. Ficke and M. Cahay, "The bright future of organic LEDs," IEEE Potentials, vol. 22, no. 5, pp. 31-34, 2003.

[49] J. Z. Song, Y. He, D. Zhu, J. Chen, C. L. Pei, and J. A. Wang, "Polymer/ZnO micro-nano array composites for light-emitting layer of flexible optoelectronic devices," Acta Physico-Chimica Sinica, vol. 27, no. 5, pp. 1207-1213, 2011.

[50] S. Esmaili-Sardari, A. Berkovich, and A. A. Iliadis, "Observation of conductivity type conversion in undoped $\mathrm{ZnO}$ films grown by pulsed laser deposition on silicon (100) substrates," Applied Physics Letters, vol. 100, no. 5, Article ID 053505, 2012.

[51] K. Kim, S. Y. Park, K.-H. Lim, C. Shin, J.-M. Myoung, and Y. S. Kim, "Low temperature and solution-processed Nadoped zinc oxide transparent thin film transistors with reliable electrical performance using methanol developing and surface engineering," Journal of Materials Chemistry, vol. 22, no. 43, pp. 23120-23128, 2012.

[52] W.-J. Yang, C.-C. Tsao, C.-Y. Hsu, H.-C. Chang, C.-P. Chou, and J.-Y. Kao, "Fabrication and characterization of transparent conductive $\mathrm{ZnO}: \mathrm{Al}$ thin films deposited on polyethylene terephthalate substrates," Journal of the American Ceramic Society, vol. 95, no. 7, pp. 2140-2147, 2012.

[53] M. Y. Zhang and G. J. Cheng, "Highly conductive and transparent alumina-doped $\mathrm{ZnO}$ films processed by direct pulsed laser recrystallization at room temperature," Applied Physics Letters, vol. 99, no. 5, 2011.

[54] T. Moon, W. Yoon, K. S. Ji et al., "Enhancement of crystallinity in $\mathrm{ZnO}$ :Al films using a two-step process involving the control of the oxygen pressure," in Proceedings of the 35th IEEE Photovoltaic Specialists Conference (PVSC '10), pp. 3709-3712, June 2010.

[55] T. Prasada Rao and M. C. Santhoshkumar, "Effect of thickness on structural, optical and electrical properties of nanostructured $\mathrm{ZnO}$ thin films by spray pyrolysis," Applied Surface Science, vol. 255, no. 8, pp. 4579-4584, 2009.

[56] J. Z. Song, Y. He, Z. D. Pan, D. Zhu, J. Chen, and J. A. Wang, "PANI/nano-ZnO composites prepared by in-situ polymerization under magnetic field," Acta Chimica Sinica, vol. 69, no. 13, pp. 1582-1588, 2011. 

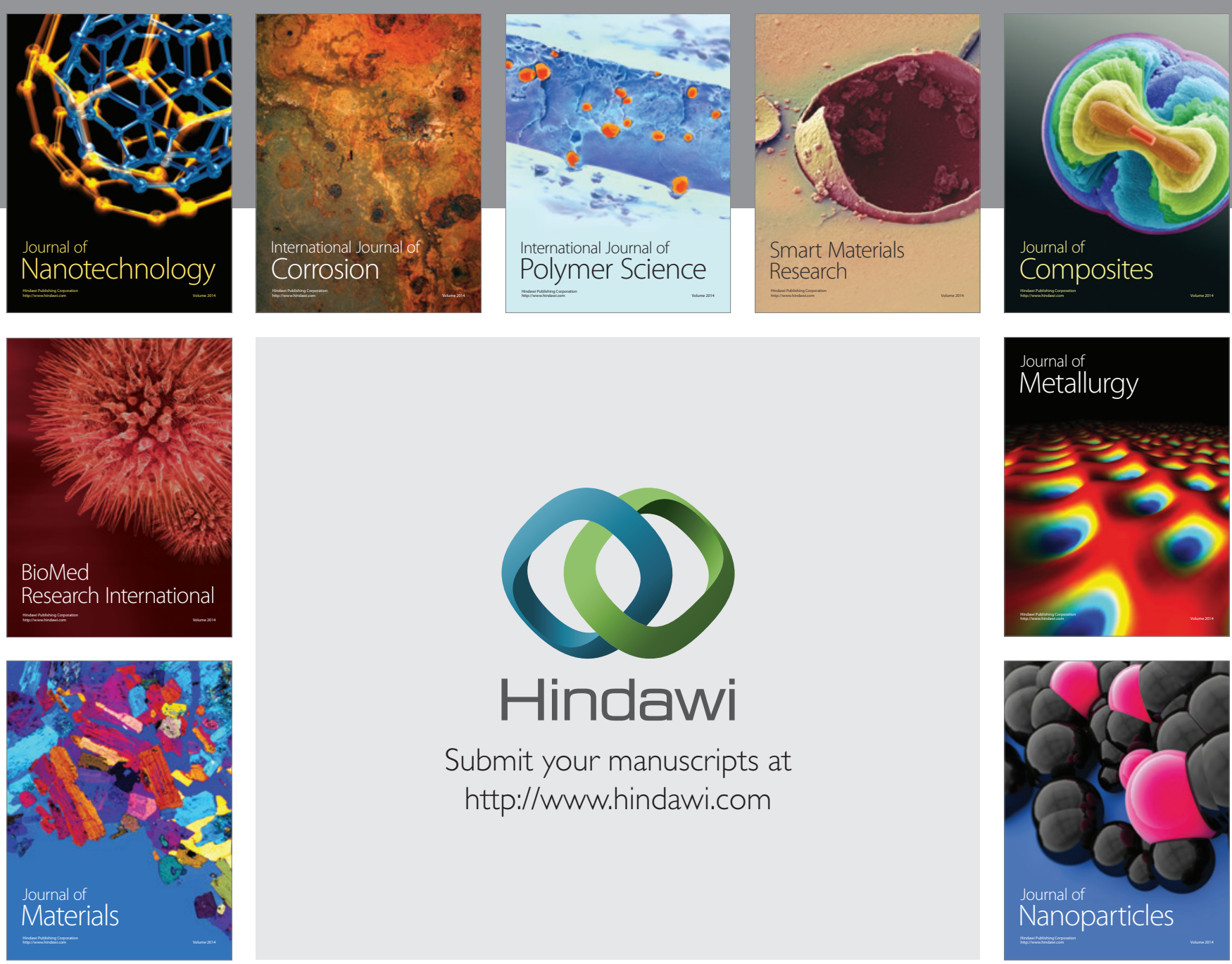

Submit your manuscripts at http://www.hindawi.com
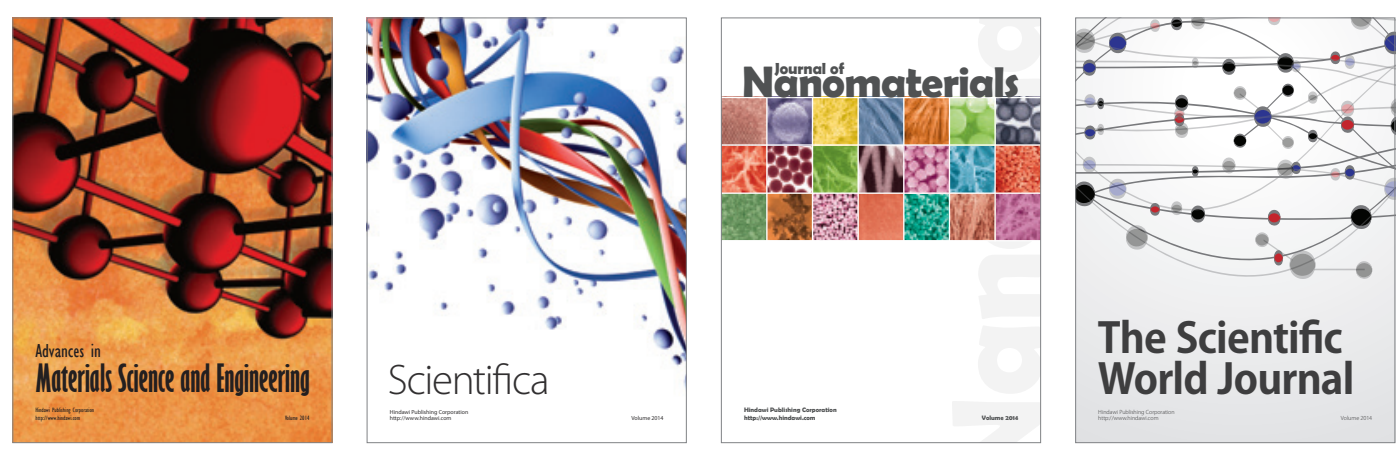

\section{The Scientific World Journal}
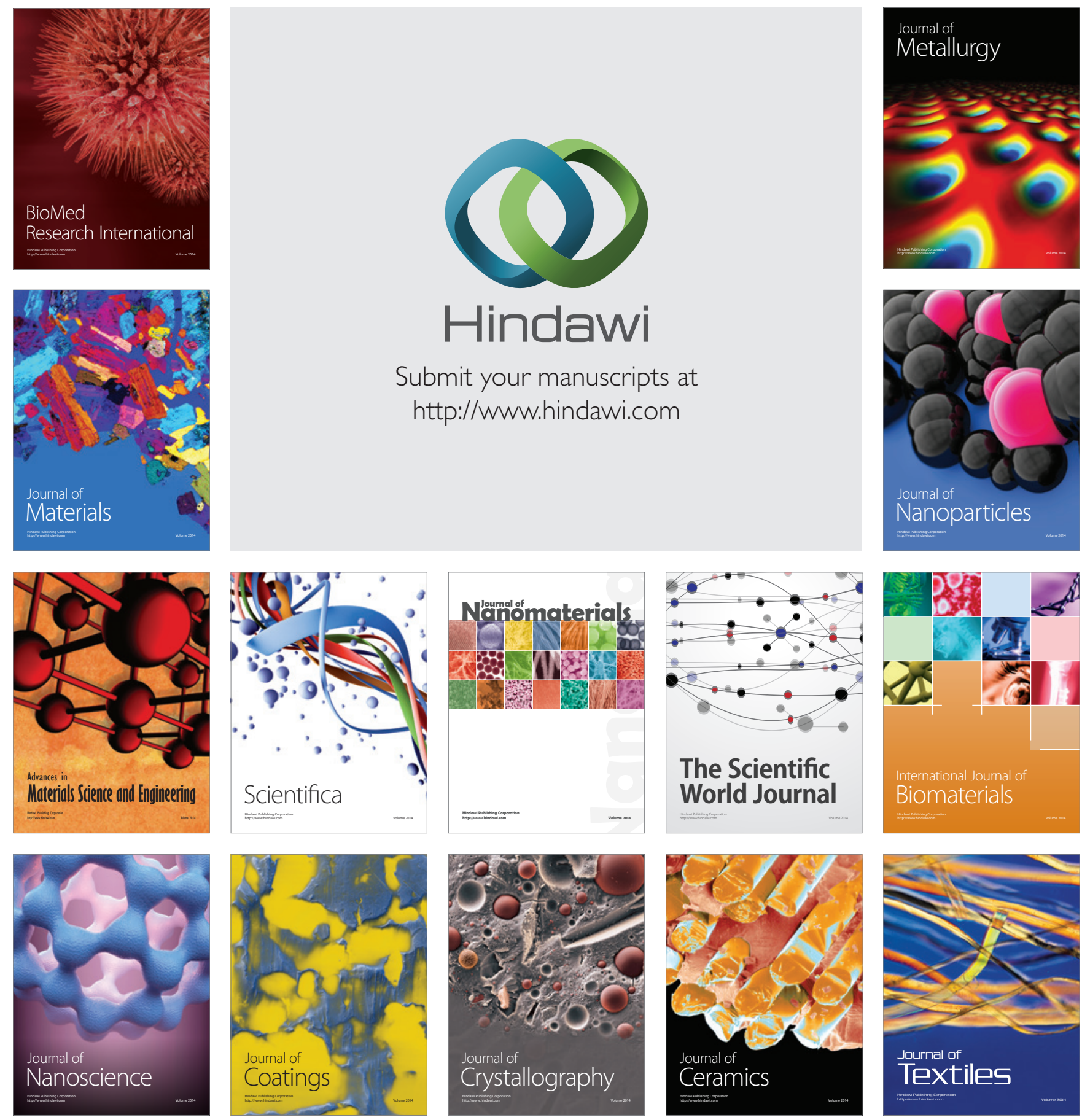